\title{
LIFE HISTORIES OF NORTH AMERICAN GEOMETRIDAE.--LXVIII.
}

\author{
BY HARRISON G. DYAR, WASHINGTON, D. C.
}

Caberodes confusaria Hübner. Dr. Packard reproduces a figure of Abbot's as the larva of this species (Mon. Geom., pl. xiii, fig. 18); but, as appears from the text, this is the larva of floridaria Guen., and in any case does not agree with that of confusaria, having humps, whereas that is smooth. Mr. Bruce mentions (Ent. Amer., iii, 47,1887 ) that the larvae were swept from clover, but gives no description. The present is, therefore, the first account of the larva.

Egg. Subcylindrical, the micropylar end evenly truncate, the flat area nearly as large as the central diameter; other end rounded, the two diameters nearly equal; about 20 longitudinal ribs, even, sharp, white crested, stopping at the edge of the truncation, slightly beaded; cross-striae fine, obscure; micropylar disk coarsely reticulated at the edge, finer centrally. Bluish green, turning to dull red, the ribs and reticulations white. Size, $.9 \times .6 \times .5 \mathrm{~mm}$. Hatched in twelve days.

Stage I. Head rounded, black, slightly shining, epistoma white; width about $.5 \mathrm{~mm}$. Body moderate, rather stout, the feet normal. Dark vinous brown, banded with grayish white; two narrow bands on thorax, between the feet a little irregularly edged and confusedly mottled; five abdominal transverse bands, half as broad as the intervening spaces, situated anteriorly on joints 5 to 9 , cut by a narrow, thread-like subdorsal line, which widens at its posterior junctions with the dark areas; the bands are narrowed ventrally and divided by a broad adventral and narrow medioventral lines. A trace of a dark dorsal line, cutting the white bands anteriorly on the segments. Joints 10 to 13 with narrow subdorsal and broad blotchy subventral white longitudinal lines. Feet dark, concolorous.

Stage II. Head quadrate rounded, slightly bilobed, wider than high; vinous black, epistoma, antennae and two vertical mottled lines over the lobes white; width, $.7 \mathrm{~mm}$. Body moderate, feet normal, situated well posteriorly, segments annulate. Dark vinous brown; a dorsal row of semi-elliptical white spots, each cut from the truncated end by a dark line, on joints 5 to 9 ; large mottled lateral blotches, partly cut by the subventral fold; slight white mottling subdorsally especially on the tubercles of joints 2-5 and 10-13; venter dotted on the tubercles. Thoracic feet black; anal feet large, dark, with a white outer line. Setae inconspicuous; no humps nor elevations. A medioventral white band cut by a longitudinal line and the annulet incisures. 
Stage III. Head rounded quadrate, wide; vinous black, a broad mottled erect white band on the face of each lobe, divergent below; a white triangle in the clypeus; epistoma and bases of antennae white; width, $1 \mathrm{~mm}$. Body robust, weakly annulate, colored as before; the dorsal and other white patches more mottled and cut by the ground color, which is darker, vinous blackish. Tubercles in the lateral patches lumpy white.

Stage IV. Head as before, black, epistoma white, white diffused dottings broadly over the angles of the lobes and slightly in the clypeus; rounded quadrate, as high as wide, antennae and mouth dark; width $1.4 \mathrm{~mm}$. Body moderate, normal, uniform; vinous black, annulate; dotted white subdorsal line on joints $2-4$, a cordate white mark, containing a dark dot in each lobe on joints $5-10$, centered by tubercle $\mathrm{i}$, the white cut by the annulet incisures, obscurely joined by a geminate dorsal band posteriorly; on joints 10-13 a waved broken subdorsal band, roughly imitating the cordate marks; a series of segmental white patches on joints $7-9$, joined by a broad white band on joints $8-12$, becoming a narrower band anteriorly and posteriorly, running narrowly onto the foot on joints 10 and 13 . Venter obscurely white streaked, with a pale medio-ventral band, dark centered; small white dots laterally, especially at tubercles ii and iii. Orange blotches in the white lateral markings. With growth the markings fade and become yellowish, but leave a bright white lateral spot on joints 5,6 and 7, largest on joint 7 .

Stage $V$. Head rounded quadrate, thick, as high as joint 2, scarcely bilobed; dull black, with angular white dots over the sides and in clypeus, forming a short black-dotted band on the vertices of the lobes; epistoma white; width, $1.8 \mathrm{~mm}$. Body robust, uniform, feet normal; leather brown (dead-leaf) dotted with black; a waved smoky black subdorsal line, the cordate white spots lost in the brown ground, leaving only a little white mottling about tubercle $i$, and whitish bars on the otherwise concolorous cervical shield and anal plate; faint linear white lateral line, black edged; large white spots about the spiracles on joints 5-10, faint posteriorly, involving tubercle iii by a lobe; an orange spot about tubercles iv and v. Venter with numerous indistinct lines of blackish and brown, subgranular, dotted by whitish. Thoracic feet dark; the abdominal ones of joint 10 white lined, of 13 large, marbled, with a whitish band anteriorly that joins a faint stigmatal band composed of the confluence of the stigmatal patches on joints 9-13; a reddish tinged stigmatal band on joints 2-4.

Stage VI. Head rounded quadrate, thick, the vertex roundedly divided, level with joint 2; colored as before but the white more extended, so that the ground color is white with crinkled and dotted dark brown marks, which are confluent over the sides and broadly each side of the median suture, and form a border within the 
clypeus; eyes black, epistoma white, labrum brown, antennae white; setae short, brown, from small shining tubercles, normal; width, $2.4 \mathrm{~mm}$. Body robust, cylindrical, uniform, tubercle $\mathrm{i}$ of joint 12 slightly enlarged, the thorax a little smaller, no humps. Coloration essentially as before; segments wrinkly annulate, smooth around the spiracles; carneous brown, olivaceous yellowish on the sides, shaded with blackish; thorax under lens pinkish white, dotted with brown-black, leaving subdorsal and stigmatal pale shaded bands, touched with ocherous; a square black patch laterally on joints 3 and 4; subventral region blackish shaded; feet dark brown. Abdomen dorsally (under lens) white, dotted thickly with ocherous and sparsely with black; a waved subdorsal black shade composed of dots and disappearing largely under a lens; sides olive shaded, a large white bilobed spot about tubercle iii and the spiracle, another on tubercle $\mathrm{v}$ and an ocherous one on tubercle iv, distinct on joint 6 , fainter on joints 5 and 7 , lost in a lilacine shade on joint 8 and running into a band on joints $9-13$. Venter dotted, showing broad pale medio-ventral band, narrower dark one each side, narrow pale one, to a broader dark one over tubercles vi-vii, all rather evanescent under a lens ; a straight subdorsal shade on joints 10-13, broken into oblique shades of dots; tubercle i of joint 12 white; anal shield and leg plates darkly marked on a white ground. Tubercles small, black; setae short, stiff, brown.

The larva spun a slight cocoon between leaves and pupated at once; adult issued in about four weeks.

Food plant, dandelion. The larvae were offered a variety of plants and chose this one. Probably they will eat a number of low plants. Larvae from Washington, D. C.

A LARGE number of European and American entomologists attended the summer meeting of the Entomological Society of America, held on August 22 in connection with the Seventh International Zoological Congress in Boston. The auditorium of the Boston Society of Natural History was well filled, and several very interesting papers were presented. Dr. Henry Skinner of Philadelphia presided. After the meeting the Cambridge Entomological Club entertained its guests at a smoker in the Grundmann Studios on Clarendon Street. 

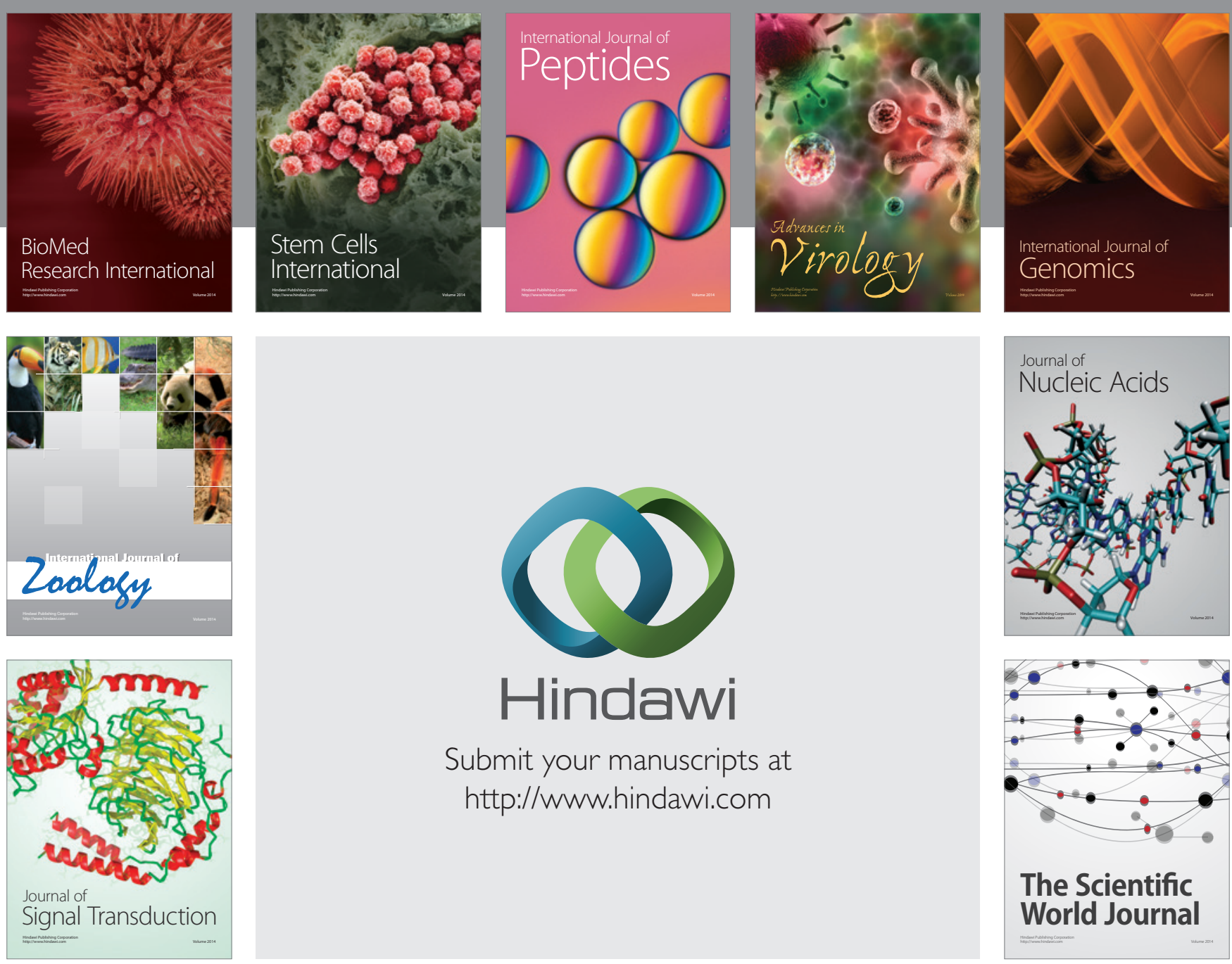

Submit your manuscripts at

http://www.hindawi.com
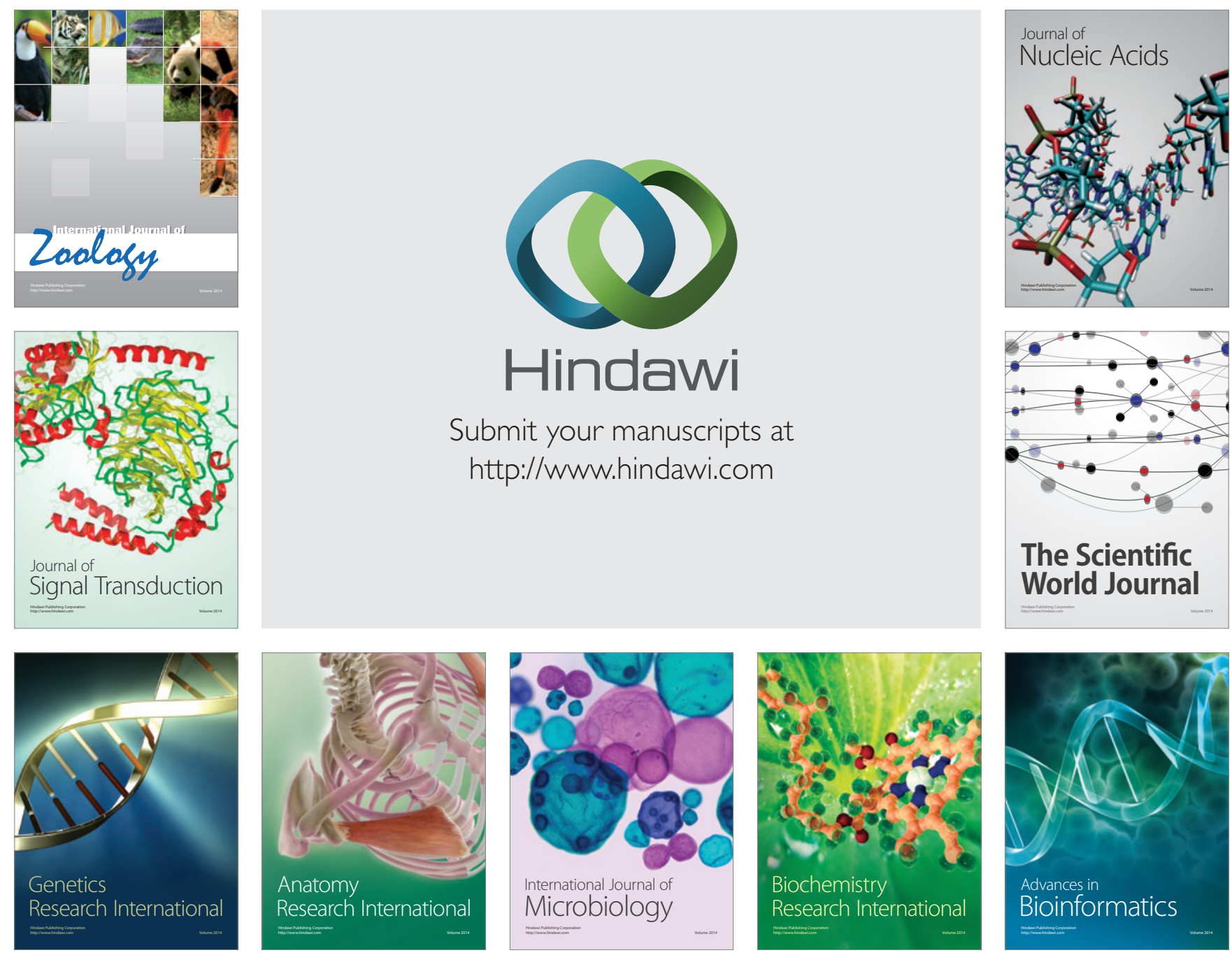

The Scientific World Journal
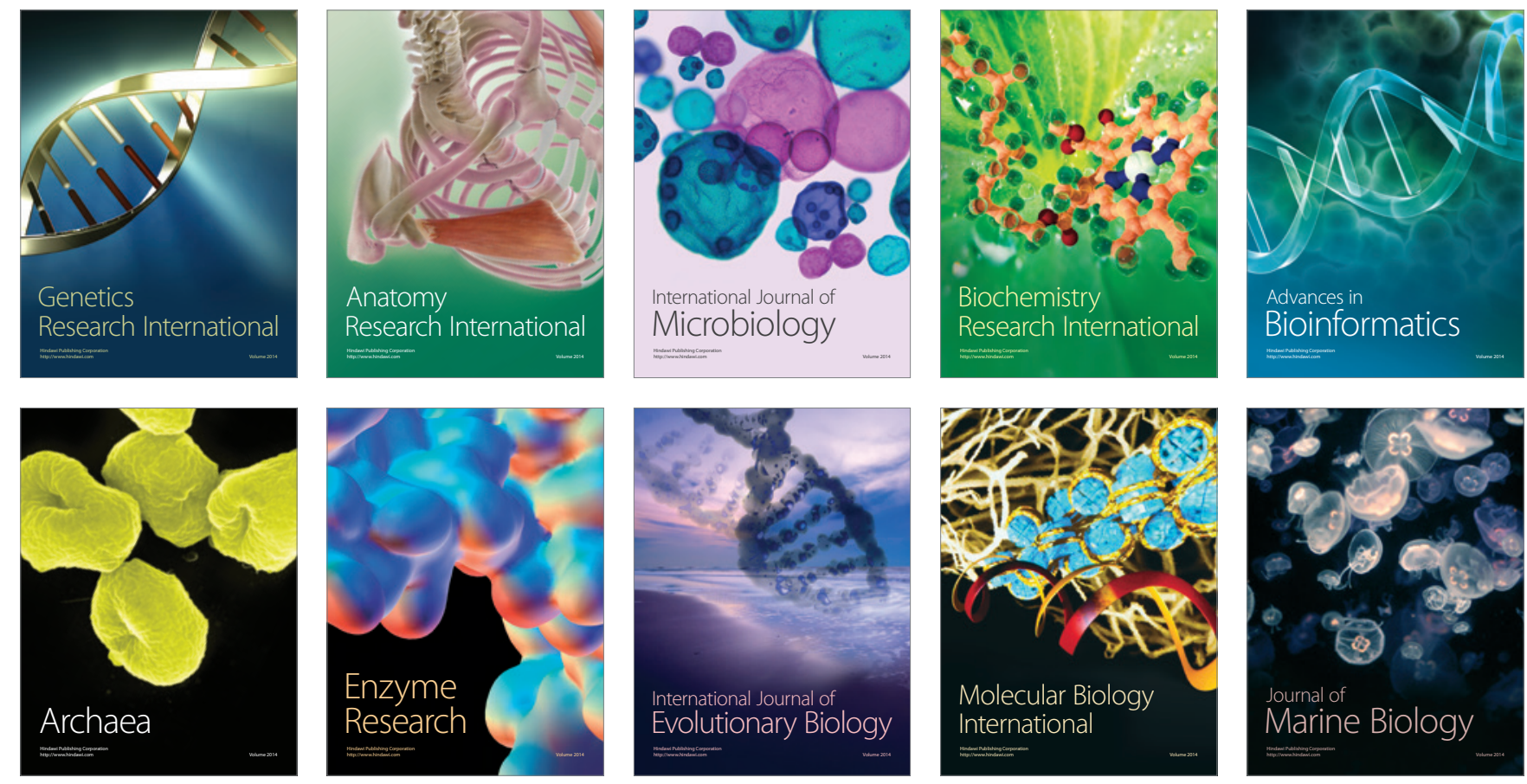